\title{
Access to community care for people with dementia and their informal carers
}

Citation for published version (APA):

Bieber, A., Stephan, A., Verbeek, H., Verhey, F., Kerpershoek, L., Wolfs, C., de Vugt, M., Woods, R. T., Røsvik, J., Selbaek, G., Sjölund, B. M., Wimo, A., Hopper, L., Irving, K., Marques, M. J., GonçalvesPereira, M., Portolani, E., Zanetti, O., \& Meyer, G. (2018). Access to community care for people with dementia and their informal carers: Case vignettes for a European comparison of structures and common pathways to formal care. Zeitschrift für Gerontologie und Geriatrie, 51(5), 530-536.

https://doi.org/10.1007/s00391-017-1266-7

Document status and date:

Published: 01/07/2018

DOI:

10.1007/s00391-017-1266-7

Document Version:

Publisher's PDF, also known as Version of record

Document license:

Taverne

Please check the document version of this publication:

- A submitted manuscript is the version of the article upon submission and before peer-review. There can be important differences between the submitted version and the official published version of record.

People interested in the research are advised to contact the author for the final version of the publication, or visit the DOI to the publisher's website.

- The final author version and the galley proof are versions of the publication after peer review.

- The final published version features the final layout of the paper including the volume, issue and page numbers.

Link to publication

\footnotetext{
General rights Owners
rights.

- You may freely distribute the URL identifying the publication in the public portal. please follow below link for the End User Agreement:

www.umlib.nl/taverne-license

Take down policy

If you believe that this document breaches copyright please contact us at:

repository@maastrichtuniversity.nl

providing details and we will investigate your claim.
}

Copyright and moral rights for the publications made accessible in the public portal are retained by the authors and/or other copyright owners and it is a condition of accessing publications that users recognise and abide by the legal requirements associated with these

- Users may download and print one copy of any publication from the public portal for the purpose of private study or research.

- You may not further distribute the material or use it for any profit-making activity or commercial gain

If the publication is distributed under the terms of Article $25 \mathrm{fa}$ of the Dutch Copyright Act, indicated by the "Taverne" license above, 
Z Gerontol Geriat 2018 $51: 530-536$ https://doi.org/10.1007/s00391-017-1266-7 Received: 23 January 2017

Revised: 12 April 2017

Accepted: 29 May 2017

Published online: 14 June 2017

c) Springer Medizin Verlag GmbH 2017

CrossMark

A. Bieber' $\cdot$ A. Stephan ${ }^{1} \cdot$ H. Verbeek ${ }^{2} \cdot$ F. Verhey ${ }^{2} \cdot$ L. Kerpershoek ${ }^{2} \cdot$ C. Wolfs ${ }^{2}$. M. de Vugt ${ }^{2} \cdot$ R. T. Woods ${ }^{3} \cdot$ J. Røsvik $^{4} \cdot$ G. Selbaek ${ }^{4}$ - B. M. Sjölund ${ }^{5,9} \cdot$ A. Wimo ${ }^{5}$. L. Hopper ${ }^{6} \cdot$ K. Irving $^{6} \cdot$ M. J. Marques $^{7} \cdot$ M. Gonçalves-Pereira $^{7} \cdot$ E. Portolani $^{8}$. O. Zanetti ${ }^{8} \cdot$ G. Meyer ${ }^{1}$

${ }^{1}$ Medical Faculty, Institute for Health and Nursing Science, Martin Luther University Halle-Wittenberg, Halle (Saale), Germany

${ }^{2}$ School for Mental Health and Neuroscience, Alzheimer Center Limburg, Department of Psychiatry and Neuropsychology, Maastricht University Medical Center, Maastricht, The Netherlands

${ }^{3}$ Dementia Services Development Centre Wales, Bangor University, Bangor, UK

${ }^{4}$ Norwegian National Advisory Unit on Ageing and Health, Vestfold Hospital Trust, and Department of Geriatric Medicine, Oslo University Hospital, Oslo, Norway

${ }^{5}$ Department of Neurobiology, Care sciences and Society, Karolinska Institut, Stockholm, Sweden

${ }^{6}$ School of Nursing and Human Sciences, Dublin City University, Dublin, Ireland

${ }^{7}$ CEDOC, Chronic Diseases Research Centre, Nova Medical School/Faculdade de Ciências Médicas, Universidade Nova de Lisboa, Lisbon, Portugal

${ }^{8}$ Alzheimer's Research Unit-Memory Clinic, Brescia, Italy

${ }^{9}$ Department of Health and Caring Services, University of Gävle, Gävle, Sweden

\section{Access to community care for people with dementia and their informal carers}

\section{Case vignettes for a European comparison of structures and common pathways to formal care}

\section{Electronic supplementary material}

The online version of this article (doi:10.1007/ s00391-017-1266-7) contains supplementary material, which is available to authorized users.

Increasing the understanding of dementia care structures can help to increase care coordination in the European healthcare systems. This is an important first step towards providing a basis for subsequent initiatives to improve access to timely and need-oriented formal dementia care. In the current paper we aimed to gain understanding in the structures and procedures in accessing formal community dementia care in eight countries and to compare the national systems. To achieve this, we explored common national pathways in accessing formal dementia care and then compared these pathways to identify similarities and differences in service access and utilization.

\section{Background}

Nearly two thirds of people with dementia in Europe live in the community, supported by informal carers. It has been estimated that half of these people have no access to professional services [2], or services were not used until late in the trajectory of the disease [9]. However, it is well known that appropriate community services can support people with dementia living at home for as long as possible, thus postponing admission to nursing homes [24]. Access to and utilization of health services is a complex subject which can be described with the Andersen Behavioral Model of Health Service Use [3]. This conceptual framework uses a systems perspective to integrate a range of individual, environmental, and provider-related variables associated with decisions to seek care [20]. Individual variables of people with dementia and their informal carers which may influence health and social care service use have been investigated several times [23, 28], but environmental and provider-related variables should also be examined, taking into consideration their assumed impact on dementia-related service use [8].

Increasing the understanding of dementia care structures can help to improve care coordination in European healthcare systems, which is an important first step towards providing a basis for subsequent initiatives to improve ac- 
cess to timely and needs-oriented formal dementia care.

\section{Aims}

The Actifcare project (Access to timely formal care) aims to increase our understanding of why people with dementia and their informal carers use or do not use formal care services. The following eight European countries participated: Germany (DE), Ireland (IE), Italy (IT), the Netherlands (NL), Norway (NO), Portugal (PT), Sweden (SE), and the United Kingdom (UK). This range of eight European countries from North, South and Central Europe allows us to compare the different health and social care systems and to learn from the experiences of living and dealing with dementia in various societies. The definition of formal dementia care in the Actifcare project [13] includes nursing care at home, day care services, community or long-term medical, nursing, and social care structures and processes, and excludes domestic home help, housekeepers, volunteers, support groups, transport services, and meal-provision programmes. The Actifcare project focuses on the period of time when people with dementia, or frequently their informal carers, may be looking for access to formal care, typically in the middle stage of dementia.

In the current paper we aimed to gain understanding of the structures and procedures associated with accessing formal dementia care in each participating country and to compare the national systems. To achieve this, we explored common national pathways in accessing formal dementia care and then compared these pathways to identify similarities and differences in service access and utilization.

\section{Method}

\section{Case vignette approach}

A case vignette approach was used for this question, as this provides insight into the common national pathways of access to and utilization of formal dementia care. Vignettes are short descriptions of a person or a social situation containing precise references to what is thought to be the most important factors of the decisionmaking or judgement-making processes of respondents [1]. The technique was used in the comparison of the national dementia strategies [19], and for the description of dementia-specific healthcare pathways [15]. This method also enabled us to reduce the complexity of dementia care structures, underlining thus the most important aspects in access to formal care.

\section{Development of the case vignettes}

Our case vignettes were derived from a mapping system of the national dementia care structures. The mapping system was first developed in the earlier European project RightTimePlaceCare (RTPC) [10] and was adapted accordingly to the research question of this project. In total, 33 services/structures were identified in a consensus process as being relevant when accessing formal dementia home care and community support and were therefore included in the mapping system. The mapping system covers six areas: diagnostic and therapeutic settings (5 services), home care and support for people with dementia (15 services), information and counselling (4 services), support for informal carers (3 services), civil activities (2 services), and institutional long-term care structures (4 services). An overview of the mapping system and an excerpt from the described structures are displayed in "Supplementary Material 1". Each structure or service was investigated in terms of its availability, accessibility (legal or organizational aspects), utilization, and the health or social care professionals predominantly involved in accessing the service.

The information acquired with the mapping system was the basis for the identification and description of the most common pathways to formal dementia care.

\section{Case vignette writing}

Actifcare partners received a brief description as the introduction to a case scenario which should be used as the starting point from which the case vi- gnette was developed (available as "Supplementary Material 2"). This starting point provided a common example of a person with dementia in terms of the living situation, social relationships, the caregiving situation, sociodemographic aspects, diagnosis of dementia, and the trajectory of the disease. Actifcare partners were instructed to develop their own county-specific vignette, not exceeding one page, which described the health and social care institutions or professionals encountered in this scenario. More importantly, each must have been available and accessible to an individual in this scenario at the time of writing.

\section{Data analysis}

The case vignettes prepared by members of the Actifcare team were sent for analysis to the German team as the responsible research team for this part of work. A qualitative content summary approach was used to derive categories directly from the material itself [17]. The eight case vignettes were first analysed and categorized. In the second analysis step the national findings were checked for corresponding categories, which were compared and synthesized. The crossnational findings were then discussed transnationally by the full research team to guarantee that no country-specific data were misinterpreted or omitted.

\section{Results}

Four main categories were identified from the common national pathways: (1) professionals involved in dementia care, (2) dementia-specific or teambased approaches, (3) proactive roles in accessing formal care, and (4) financial aspects.

1. Experts judged GPs and specialists as key figures in terms of accessing formal dementia care. In all of the eight countries GPs are usually the first points of contact. They can make referrals to memory clinics, which play the central role in two countries (NL, UK). In some countries, GPs diagnose dementia on their own (SE, NL, NO, partially in PT), but more often they refer people with 
Z Gerontol Geriat 2018·51:530-536 https://doi.org/10.1007/s00391-017-1266-7

(c) Springer Medizin Verlag GmbH 2017

A. Bieber · A. Stephan · H. Verbeek · F. Verhey · L. Kerpershoek · C. Wolfs · M. de Vugt · R. T. Woods · J. Røsvik · G. Selbaek · B. M. Sjölund · A. Wimo • L. Hopper $\cdot$ K. Irving $\cdot$ M. J. Marques $\cdot$ M. Gonçalves-Pereira $\cdot$ E. Portolani $\cdot$ O. Zanetti $\cdot$ G. Meyer

\section{Access to community care for people with dementia and their informal carers. Case vignettes for a European comparison of structures and common pathways to formal care}

Abstract

Background. People with dementia and their informal carers often do not receive appropriate professional support or it is not received at the right time.

Objectives. Description and comparison of common pathways to formal community dementia care in eight European countries as a part of the transnational Actifcare project. Materials and methods. The German team was responsible for creating an individual case scenario as a starting point. The research teams in Ireland, Italy, the Netherlands, Norway, Portugal, Sweden, and the United Kingdom were then asked to describe a common pathway to formal dementia care by writing their own vignette using the provided individual case scenario.

Results. A transnational qualitative content analysis was used to identify the following categories as being the most important: involved professionals, dementia-specific and team-based approaches, proactive roles, and financial aspects. General practitioners (GPs) are described as being the most important profession supporting the access to formal care in all the involved countries. In some countries other professionals take over responsibility for the access procedure. Dementia-specific approaches are rarely part of standard care; team-based approaches have differing significances in each of the countries. Informal carers are mainly proactive in seeking formal care. The Nordic countries demonstrate how financial support enhances access to the professional system.

Conclusion. Enhanced cooperation between GPs and other professions might optimize access to formal dementia care. Team-based approaches focusing on dementia care should be developed further. Informal carers should be supported and relieved in their role. Financial barriers remain which should be further investigated and reduced.

\section{Keywords}

Dementia $\cdot$ Health services accessibility $\cdot$ Care . Comparative study · Europe

\section{Zugang zu professioneller Unterstützung für Menschen mit Demenz und ihre Angehörigen. Fallvignetten für den europäischen Vergleich von Strukturen und Zugangswegen zu professioneller Pflege}

\section{Zusammenfassung}

Hintergrund. Menschen mit Demenz und ihre Angehörigen erhalten häufig nicht oder nicht rechtzeitig angemessene professionelle Unterstützung.

Ziel der Arbeit. Beschrieben und verglichen werden Zugangswege zu professioneller ambulanter Unterstützung bei Demenz in acht europäischen Ländern als Teil des transnationalen Actifcare-Projekts.

Material und Methode. Das für das Arbeitspaket verantwortliche Team aus Deutschland erstellte eine Fallvignette als Prototyp; die wissenschaftlichen Teams in Irland, Italien, den Niederlanden, Norwegen, Portugal, Schweden und Großbritannien erhielten den Auftrag, darauf aufbauend den typischen Zugangsweg zu professioneller Unterstützung bei Demenz in einer individuellen Vignette fortzuschreiben.

Ergebnisse. Mit einer länderübergreifenden qualitativen Inhaltsanalyse wurden als wesentliche Kategorien identifiziert: involvierte Professionen, demenzspezifische und teambasierte Ansätze, proaktive Rollen und finanzielle Aspekte. Als die wichtigste Profession im Zugang zu professioneller Unterstützung wird in allen Ländern der Hausarzt beschrieben. In einigen Ländern übernehmen andere Professionen Verantwortung im Zugangsprozess. Demenzspezifische Strukturen sind kaum Bestandteil der Regelversorgung; teambasierte Ansätze sind in den meisten Ländern unterschiedlich bedeutsam etabliert. Angehörige kümmern sich oft in Eigeninitiative darum, professionelle Hilfen einzubeziehen. Die nordischen Länder zeigen, wie sich durch finanzielle Unterstützung der Zugang zum professionellen System fördern lässt.

Schlussfolgerung. Eine intensivierte Zusammenarbeit zwischen Hausärzten und anderen Professionen könnte den Zugang optimieren. Teambasierte Ansätze sind demenzspezifisch weiterzuentwickeln. Angehörige sind in ihrer Rolle zu unterstützen und zu entlasten. Finanzielle Zugangshürden sind genauer zu identifizieren und zu reduzieren.

Schlüsselwörter

Demenz · Zugang zu Gesundheitsangeboten · Professionelle Pflege · Vergleichsstudie . Europa suspected dementia to specialists, or to dementia-specific hospitals, i. e. Alzheimer Evaluation Units (IT), multidisciplinary memory clinics (IE, NL, UK), or specialists in neurology or psychiatry (IE, PT). If nationally available, GPs and specialists might then refer diagnosed people to formal dementia care services such as Community Mental
Health Teams in NL and UK or the Local Authority dementia teams in NO. The Norwegian dementia teams assist GPs in the assessment of people suspected of having dementia. Other professionals, who were nonmedical reference persons specific for people with dementia and informal carers, or who acted as a channel to the available care services, were only mentioned in a few countries: the Community Mental Health Nurse (UK), the municipal case manager (SE) and the Public Health Nurse (IE). These professional roles were not designated exclusively to dementia, and they were responsible for several tasks in addition to providing access to formal care, such as referring to services (UK), care planning 
by case managers (SE), and conducting need assessment (IE). Such reference persons specific for people with dementia and their families do not exist at all in Portugal and only partly in Germany.

2. The Norwegian dementia teams in the communities were described as dementia-specific structures important as national pathways of access to formal care. The same applies, regardless of their varying importance in other countries, to memory clinics in IT, NL and UK, and national Alzheimer societies in IE and UK. Some of the services actively supply supportive tasks such as cognitive rehabilitation, information addressing informal carers (Alzheimer Evaluation Units, IT), or local Alzheimer Cafés (Alzheimer Society, IE). The Alzheimer Societies of Ireland are also service providers themselves and they provide dementia-specific home care, day care, and respite care, in addition to that provided generally by the health system. Other dementiaspecific services take responsibility for coordinating care and treatment supplied by different organizations and agencies, e.g. the Norwegian dementia teams connect informal carers with local authority home service offices.

Dementia-specific structures were described only for Norway, where $75 \%$ of the communities report that they have a dementia team or a dementia coordinator. They are responsible not only for the person with dementia, but also for support to informal carers who are assigned a named contact person from the team. The dementia teams cooperate closely with local service providers and GPs.

Community Mental Health Teams, which are also team-based structures, are available nationwide for people with dementia in two countries (NL, UK). They initiate need assessment and make referrals to appropriate formal care services, but they are typically responsible for a wider range of services than dementia care alone.
3. The vignettes express a tendency for informal carers to be more proactive than healthcare professionals when seeking access to services. Those living with or caring for the person with dementia are in close contact with them and can more easily observe changes in competencies and daily activities. They can then seek support from the GPs (DE, IE, SE, PT), support services for themselves (IE), social support or help at home for the person with dementia (IE, IT, NL, to some extent PT). The more proactive role of informal carers does not mean that there are no professionals in the national systems who give support in finding access to services. Professionals recommend the next steps to be taken to gain access to formal care, such as contacting nurses educated in counselling (DE), specialized nurses (NL) or social workers (PT), or they take on responsibility in linking to other professionals or support services (NL, NO, UK). However, this is only fragmented and seldom dementia-specific support in most of the countries.

4. Financial aspects were described in the case vignettes as influencing factors in access and utilization of formal care in dementia. In some countries social security benefits are available for people with dementia and informal carers in need of support, subject to approval through need assessment (e.g. DE, NL, UK, regionally in IT, to some extent in PT); sometimes indirect financial support can be received through subsidized home care (DE, IE, NO, NL, PT, UK) or tax subsidies (IT). No out-of-pocket expenditures for home care and small out-of-pocket expenditures for domestic help were described as typical in NO and SE, facilitating the utilization of formal dementia care. In contrast, higher out-of-pocket expenditures were serious barriers for utilization of formal care or were financial strains for the families (DE, IE, IT, PT).

\section{Discussion}

To our knowledge, this is the first European cross-national comparison of national pathways concerning access to formal care in dementia using a case vignette approach. GPs are often described as the first point of contact, although this did not inevitably lead to appropriate access to formal care. The comparison suggests that the typical pathways are usually not dementia-specific. In most of the eight countries, informal carers assume the main responsibility for accessing services and seeking professional help for people with dementia and for themselves. It seems there are several financial influences that vary considerably throughout the national pathways, such as financial benefits or out-of-pocket expenditures.

The role of GPs in access to formal dementia care is not always clear [6], or they were seen as central figures in the coordination of service delivery, but they often do not fulfill this role [16]. In most of the national pathways, GPs are highlighted as the first point of contact in the help-seeking process. This is in accordance with the view of informal carers, who regard the GPs as the key person in managing care for people with dementia in DE [27]. The interaction between informal carers and GPs also influences access to formal dementia care [7]. GPs often lack knowledge about available support services [30] and this might be one reason why GPs are not considered to provide continuity of service access throughout the whole process of help-seeking within the national pathways. Nurses, who are qualified for specific tasks in dementia care, might be an alternative. This approach has been applied in DE through Dementia Care Management conducting home visits, identifying care needs, evidence-based recommendations, and giving feedback to the GP [28].

Dementia-specific care services are crucial when considering the special needs of people with dementia and their informal carers [12]. The dementia teams in Norway seem to reflect best practice in access to care, in that they combine a key reference person (or advisor) with a multiprofessional team approach. This service is currently being 
developed further; a pilot study is being conducted, using a model that addresses not only dementia but also other psychiatric diseases in old age. The results have not been reported as yet. The majority of people with dementia are geriatric patients as well, having a complex interplay of psychological, physiological and social needs. Thus, care structures have to reflect the special needs of older people in general and, in fact, most of the care structures across Europe are not dementia-specific [5]. However, healthcare professionals working particularly with older people require dementia-specific knowledge and skills, which may be a crucial point in access to formal care [12]. This seems all the more important as nondementia-related care needs or somatic diseases often trigger the use of formal care by people with dementia and their informal carers, e.g. in the case of hospital admission [11].

Team-based and multiprofessional structures are said to provide individual, need-tailored, comprehensive and continuous care for people with dementia [4], e. g. memory clinics that might enhance access to formal care [18]. Memory clinics are part of standard dementia care in most participating countries and are explicitly described in common pathways to care (IT, NL, UK). Noteworthy is the fact that the concept of 'memory clinic' is not the same across countries and its usefulness may vary according to the characteristics of each national health system. However, the case vignettes impart only little information about the importance of memory clinics in the process of access to care. Since different professions work together in memory clinics, they could play a central role for access to professional care. The coordinating role of memory clinics might be more explicit. If memory clinics should exist outside of the public health system (IE), they would not be on the typical pathways to care.

Informal carers of people with dementia are the people who make the most decisions about care [24], which are often based on an increase in the burden they themselves have to cope with [26]. On the other hand, informal carers comment that they are not involved enough in decision-making processes with professionals [25]. The national common pathways confirm that informal carers mainly initiate and carry out the help-seeking process, but in a few countries reference persons, such as the case managers (SE), dementia-team members (NO), community mental health nurses (UK), or public health nurses (IE) are also described as being important in facilitating access to formal care. Further research is required in order to find out whether these professionals have sufficient training and are equipped with appropriate resources for linking informal carers to available support [6], and for helping informal carers to avoid having to communicate with too many professionals [4]. Case management approaches seem to be useful in providing advice on services and in conveying service-related information when coordinating these services, in developing and implementing care plans, and in supporting decision-making [16]. A recent review [21] suggests that use of community-based services combined with a case management approach reduces the admission rate to nursing homes. However, the long-term effects are unknown. Case managers may be able to address most of the needs of people with dementia and informal carers [14], particularly in collaboration with GPs, always assuming that appropriate services are available.

The common pathways also point out the cost aspects of formal dementia care. Informal carers experience financial losses because of increased costs of care [22], which are barriers for the utilization of support services. In addition, only a small proportion of informal carers are being paid to care for their relatives with dementia [29]. The national common pathways describe different ways of financially supporting access to formal dementia care, e. g. subsidized services, financial benefits, or tax subsidies. Financial barriers such as out-ofpocket expenditures are described, but not for the majority of the participating countries. Financial constraints are important factors of limited access to formal dementia care in some countries (e. g. IE, PT), but not for other countries (NO, SE). These national differences described in the case vignettes suggest that financial aspects are important in seeking access to formal dementia care.

\section{Strengths and limitations}

Although the case vignette method cannot unveil all aspects of the procedure of access, it seems to be an appropriate methodological approach for comparing cross-national pathways to identify essential structures, involved professions, and perceived responsibilities.

Case vignettes focus on the most essential aspects. Describing a typical situation does not imply generalizability. Therefore, national descriptions encompassing all the national influencing factors on access to formal dementia care could not be considered. For example, differences in culture and social status, and even regional differences within the respective countries could not be taken into account. We created a vignette with an individual case scenario to describe an example of a typical pathway to formal dementia care, which allows us to compare essential national aspects. This methodology requires the reduction of complexity, and so enables an insight into the formal care systems. We have to consider that this approach is maybe more appropriate for describing access to formal care in countries with similar structures and processes across the country (e. g. NO, SE), but less appropriate for countries with important differences in culture and social status across the country, or with regional differences (e.g. IT, PT).

Further research could also consider vignettes for people with early onset dementia or people in early stages of the disease, as they often require nontraditional entry to dementia care pathways.

\section{Conclusion}

Across the participating European countries, informal carers assume the main responsibility for help-seeking on behalf of people with dementia. When available, dementia-specific and team-based approaches seem to be appropriate to support informal carers in the help-seeking process. The role of the GP is not as clear. Although the GP is mentioned as 
a key first point of contact, it seems that he/she cannot successfully meet the expectations placed upon them in current healthcare environments. Other professions can also assume the responsibility of first contact point, such as community mental health nurses or case managers. Further development of dementia-specific services like community-based dementia teams or Dementia Care Managers might become standard care and ease the access to and utilization of formal care.

Case vignettes are a suitable approach to describe and compare national common pathways to formal dementia care. However, important differences within the countries make it difficult to describe typical pathways, as in the case of IT and PT, where income and region of residence significantly influence access to formal care. Our comparison of national common pathways to formal dementia care gives an incentive for further discussions and investigations to improve access to community care for people with dementia and their informal carers.

\section{Practical conclusions}

\section{- Dementia-specific, team-based and coordination competencies are needed for professionals who are involved in the access procedure to formal dementia care. \\ - Informal carers should receive ap- propriate and individual offers for support and relief. \\ - The impact of financial aspects on access to formal dementia care should be further investigated.}

\section{Corresponding address}

\section{Prof. Dr. G. Meyer}

Medical Faculty, Institute for Health and Nursing Science, Martin Luther University Halle-Wittenberg Magdeburger Straße 8, 06112 Halle (Saale), Germany

gabriele.meyer@medizin.uni-halle.de

\section{Compliance with ethical guidelines}

Conflict of interest. A. Bieber, A. Stephan, H. Verbeek, F. Verhey, L. Kerpershoek, C. Wolfs, M. de Vugt, R.T.Woods, J. Røsvik, G. Selbaek, B.M. Sjölund, A. Wimo, L. Hopper, K. Irving, M. Marques, M. Gonçalves-Pereira, E. Portolani, O. Zanetti and G. Meyer declare that they have no competing interests.

This article does not contain any studies with human participants or animals performed by any of the authors.

\section{References}

1. AlexanderCS,BeckerHJ(1978) The use of vignettes in survey research. Public Opin Qart 42(1):93-104

2. Alzheimer Europe (2006) Who cares? The state of dementia care in Europe. http://www. alzheimer-europe.org/Publications/AlzheimerEurope-Reports. Accessed 27 Mar 2017

3. Andersen RM, Newman JF (2005) Societal and individual determinants of medical care utilization in the United States. Milbank Q 83(4):1-28

4. Baumgardt J, Radisch J, Touil E, Moock J, Plewig HJ, Kawohl W, Rössler W (2014) Aspekte der Nachhaltigkeit in der ambulanten Versorgung von Menschen mit Demenz. Psychiatr Prax 41(8):424-431

5. Bökberg C, Ahlström G, Leino-Kilpi H, Soto-Martin ME, Cabrera E, Verbeek H, Saks K, Stephan A, Sutcliffe C, Karlsson S (2015) Care and service at home for persons with dementia in Europe. J Nurs Scholarsh 47(5):407-416

6. Brodaty $H$, Thomson C, Thompson C, Fine M (2005) Why caregivers of people with dementia and memory loss don't use services. Int J Geriatr Psychiatry 20(6):537-546

7. Carpentier N, Pomey MP, Contreras R, Olazabel I (2008) Social care interface in early-stage dementia: practitioners' perspectives on the links between formal and informal networks. J Aging Health 20(6):710-738

8. Carpentier N, Grenier A (2012) Successful linkage between formal and informal care systems: the mobilization of outside help by caregivers of persons with Alzheimer's disease. Qual Health Res 22(10):1330-1344

9. Gaugler JE, Kane RL, Kane RA, Newcomer R (2005) Early community-based service utilization and its effects on institutionalization in dementia caregiving. Gerontologist 45(2):177-185

10. Hallberg IR, Leino-Kilpi $H$, Meyer $G$, Raamat $K$, Martin MS, Sutcliffe C, Zabalegui A, Zwakhalen S, Karlsson S (2013) Dementia care in eight european countries: developing a mapping system to explore systems. JNurs Scholarsh 45(4):412-424

11. Hofmann W (2013) Demenz im Akutkrankenhaus: Was war neu 2012? Eine Literaturübersicht. ZGerontol Geriatr 46(3):198-202

12. Karlsson S, Bleijlevens M, Roe B, Saks K, Martin MS, Stephan A, Suhonen R, Zabalequi A, Hallberg IR, RightTimePlaceCare Consortium (2014) Dementia care in European countries, from the perspective of people with dementia and their caregivers. J Adv Nurs 71(6):1405-1416

13. Kerpershoek $L$, de Vugt $M$, Wolfs $C$, Jelley $H$, Orrel M, Woods B, Stephan A, Bieber A, Meyer G, Engedal K, Selbaek G, Handels R, Wimo A, Hopper L, Irving
K, Marques M, Gonçalves-Pereira M, Portolani E Zanetti O, Verhey F, Actifcare Consortium (2016) Access to timely formal dementia care in Europe: protocol of the Acticare (ACess to Timely Formal Care) study. BMC Health Serv Res 16(1):423

14. Khanassov V, Vedel I (2016) Family physician-case manager collaboration and needs of patients with dementia and their Caregivers: a systematic mixed studies review. Ann Fam Med 14(2):166-177

15. KPMG (2011) Dementia Services pathways - an essential guide to effective service planning. http://www.wimmerapcp.org.au/wp-gidbox/ uploads/2014/04/KPMG-2011-DementiaServices-Pathways.pdf. Accessed 27 Mar 2017

16. Low LF, White F, Jeon YH, Gresham M, Brodaty H (2013) Desired characteristics and outcomes of community care services for persons with dementia: What is important according to clients, service providers and policy? Australas J Ageing 32(2):91-96

17. Mayring P (2014) Qualitative Content Analysis: theoretical foundation, basic procedures and software solutions. Beltz, Klagenfurt

18. Morgan DG, Walls-Ingram S, Cammer A, O'Connell ME, Crossley M, Dal Bello-Haas V, Forbes D, Innes A Kirk A, Stewart N (2014) Informal caregivers' hope and expectations of a referral to a memory clinic. Soc Sci Med 102:111-118

19. Nakanishi M, Nakashima T (2014) Features of the Japanese national dementia strategy in comparison with international dementia policies: How: should a national dementia policy interact with the public health- and social care system. Alzheimers Dement 10(4):468-476

20. Phillips KA, Morrison KR, Andersen R, Aday LA (1998) Understanding the context of healthcare utilization: assessing environmental and providerrelated variables in the behavioral model of utilization. Health Serv Res 33(3):571-596

21. Reilly S, Miranda-Castillo C, Malouf R, Hoe J, Toot S, Challis D, Orrell M (2015) Case management approaches to home support for people with dementia. CochraneDatabase SystRev(1):CD008345 doi:10.1002/14651858.CD008345.pub2

22. Rimmer E, Wojciechowska M, Sgana A, O'Connell B (2005) Implications of The Facing Dementia Survey for the general population, patients and caregivers across Europe. International J Clin Pract 59(146):17-24

23. Robinson KM, Buckwalter KC, Reed D (2005) Predictors of use of services among dementia caregivers. West J Nurs Res 27(2):126-140

24. Saks K, Tiit EM, Verbeek $H$, Raamal K, Armolik A, Leibur J, Meyer G, Zabalegui A, LeinoKilpi H, Karlsson S, Soto M, Tuckler S (2015) Most appropriate placement for people with dementia: individual experts vs. expert groups' decisions in eight European countries. J Adv Nur 71(6):1363-1377

25. Schoenmakers B, Buntinx F, Delepeleire J (2009) What is the role of the general practitioner towards the family caregiver of a community-dwelling demented relative? Scand J Prim Health Care 27(1):31-40

26. Singh P, Hussain R, Khan A, Irwin L, Foskey R (2014) Dementia care: intersecting informal family care and formal care systems. J Aging Res. doi:10.1155/ 2014/486521

27. Thyrian JR, Hoffmann W (2012) Dementia care and general physicians - a survey on prevalence, means, attitudes and recommendations. Cent Eur JPublic Health 20(4):270-275

28. Thyrian JR, Eichler T, Pooch A, Albuerne K, Dreier A, Michalowsky B, Wucherer D, Hoffmann W 
(2016) Systematic, early identification of dementia and dementia care management are highly appreciated by general physicians in primary care - results within a cluster-randomized-controlled trial (DelpHi). J Multidiscip Healthc 19(9):183-190

29. Toseland RW, McCallion P, Gerber T, Banks S (2002) Predictors of health and human services use by persons with dementia and their family caregivers. Soc Sci Med 55(7):1255-1266

30. TurnerS, lliffe S, Downs M, WilcockJ, Bryans M, Levin E, Keady J, O'Carrol R (2004) General practitioners' knowledge, confidence and attitudes in the diagnosis and management of dementia. Age Ageing 33(5):461-467

\section{IAGG-ER Award for Advances in Gerontology and Geriatrics}

The aims of this Award are to elevate the prestige and significance of gerontological science and to secure public acknowledgement of the excellence and achievements of gerontologists in Europe in the three following disciplines: biological, clinical and social \& behavioural sciences. European scientists who have contributed most significantly to the development of gerontology in one of three disciplines: biology, clinical gerontology and socio-behavioural sciences, can be nominated for the Award.

The IAGG ER Award is honoured by an silver medal bearing the emblem of the IAGG European Region which is accompanied by an official Diploma. The Award Ceremony takes place every 4 years during the next IAGG-ER European Congress. The list of awardees is published in the Congress programme and on the IAGG website, as well as in the IAGG Newsletter.

The award committee consists of the executive committee of IAGG-ER. In case of equality of votes, the vote of the president is decisive.

The Presidents of all National Gerontological Societies in Europe are invited to nominate candidates in the three above-mentioned disciplines. Nominees do not have to be members of the National Society nominating them.

The criteria for the award include:

1. High achievement in gerontological and/or geriatric research

2. Recognition in the European Region

3. Quality of the publications

4. Living and working in Europe

Nominations have to be sent to the President of IAGG-ER (until 2019: Clemens Tesch-Roemer, ctr@dza.de) or the Secretary of IAGG-ER (until 2019: Boo Johansson).

\section{Deadline for nominations is November, 2018}

Timeline:

- Call starts: 01st June 2018- Call ends: 30st November 2018

- Decision made: 28st February 2019

- Award presented and acceptance speech delivered during the next IAGG-ER European

Congress in Gothenburg (23rd-25th May 2019) 